\title{
Optimization of process parameters for friction Stir welding of dissimilar Aluminum alloys (AA2024 -T6 and AA6351-T6) by using Taguchi method
}

\author{
P. Murali Krishna ${ }^{a^{*}}$, N. Ramanaiah ${ }^{\mathrm{b}}$ and K. Prasada Rao ${ }^{\mathrm{c}}$
}

\begin{abstract}
${ }^{a}$ Ph.D scholar, Andhra University, Mechanical Engg. Dept., Visakhapatnam, A.P, India
${ }^{b}$ Associate Professor, Andhra University, Mechanical Engg. Dept., Visakhapatnam, A.P, India

${ }^{c}$ IITM, Department of Metallurgical and Materials Engineering, Chennai, Tamil Nadu, India

C H R O N I C L E

\section{A B S T R A C T}

\section{Article history:}

Received August 252012

Received in revised format

November 162012

Accepted November 162012

Available online

16 November 2012

Keywords:

Friction stir welding

Taguchi

Optimization

Process Parameters
The present study focused on the Taguchi experimental design technique of Friction Stir Welds of dissimilar aluminum alloys (AA2024-T6 and AA6351-T6) for tensile properties. Effect of process parameters, rotational speed, Traverse speed and axial force, on tensile strength was evaluated. Optimized welding conditions for maximize tensile strength were estimated in order to improve the productivity, weld quality. Non-linear regression mathematical model was developed to correlate the process parameters to tensile strength. The results were verified by conducting the confirmation tests at identified optimum conditions.

\section{Introduction}

Friction Stir Welding (FSW) was invented in 1991 at The Welding Institute (TWI) of UK, and initially useful for the joining of aluminum alloys traditionally difficult to weld materials in which the fusion welding techniques produce brittle dendritic structures producing a strong decrease in the mechanical properties (Thomas et al., 1991). Significant interest has been shown in the use of advanced welding techniques for aircraft structures, Process industry etc. Whilst a variety of welding methods have been identified for airframe structures, friction stir welding is an important technique that is low energy consumption solid-state process (Lee et al., 2003). Many scientists demonstrated the lower distortion and low presence of residual stresses in FSW joints with respect to the traditional welding techniques (Jata et al., 2000; Bussu \& Irving, 2003; John et al., 2004). Defect free welds with good mechanical properties have been made in a variety of aluminum alloys, even those previously thought to be not having much weldability. There have been a lot of efforts to understand the effect of process parameters on material flow behavior, microstructure formation and hence mechanical properties of FSW joints. In order to study the effect of FSW process parameters, most workers follow the traditional

* Corresponding author.

E-mail: muralikrishnapoojari@gmail.com (P. Murali Krishna)

(C) 2013 Growing Science Ltd. All rights reserved.

doi: $10.5267 /$ j.ijiec.2012.011.002 
experimental techniques, i.e. varying one parameter at a time while keeping others constant. This conventional parametric design of experiment approach is time consuming and calls for enormous resources.

Taguchi method is a power full tool which can upgrade/improve the performance of the product, process, design and system with a significant slash in experimental time and cost (Montgomery, 2006). It appears that the optimization of FSW process parameters of dissimilar aluminum alloy (AA2024-T6 \& AA6351-T6) using Taguchi method has not been reported yet. Considering the above fact, the Taguchi method is adopted to analyze the effect of process parameters (i.e. rotational speed (RS), traverse speed (TS) and axial force (AF)) for optimizing tensile strength of FS Welds of dissimilar aluminum alloys (AA2024-T6 \& AA6351-T6)

\section{Taguchi method}

The Taguchi Method is a multi-stage process, namely, systems design, parameter design, and tolerance design. The Taguchi method is used to improve the quality of products and processes. Improved quality results when a higher level of performance is consistently obtained. The highest possible performance is obtained by determining the optimum combination of design factors. The consistency of performance is obtained by making the product/process insensitive to the influence of the uncontrollable factor. In Taguchi's approach, optimum design is determined by using design of experiment principles, and consistency of performance is achieved by carrying out the trial conditions under the influence of the noise factors (Ross, 1988).

Taguchi defines three categories of quality characteristics in the analysis of Signal/Noise ratio, i.e. the lower-the-better, the larger-the-better and the nominal-the-better. The $\mathrm{S} / \mathrm{N}$ ratio for each of process parameter is computed based on $\mathrm{S} / \mathrm{N}$ analysis. Regardless of the category of the quality characteristics, a larger $\mathrm{S} / \mathrm{N}$ ratio corresponds to better quality characteristics. Therefore, the optimal level of process parameter is the level of highest $\mathrm{S} / \mathrm{N}$ ratio. Furthermore, a statistical analysis of variance (ANOVA) has been performed to see which process parameter is statistically significant for each quality characteristics and its relative contribution on the total performance.

\section{FSW Process parameters}

The first step in the selection of process parameters is to conduct the brain storming session to select the process parameters which play a major role in deciding the weld quality. In the present investigation, three process parameters were selected for study. When the RS was lower than $800 \mathrm{rpm}$, wormhole at the retreating side of weld nugget was observed and it may be due to insufficient heat generation and insufficient metal transportation; when the RS was higher than $1600 \mathrm{rpm}$, tunnel defect was observed and it might be due to excessive turbulence. Similarly, when the TS was lower than 0.35 $\mathrm{mm} / \mathrm{s}$, pin holes type of defect was observed due to excessive heat input per unit length of the weld and no vertical movement of the metal. When TS was higher than $1.5 \mathrm{~mm} / \mathrm{s}$, tunnel at the bottom in retreating side was observed due to insufficient heat. Based on the trials and available literature, the following range of process parameters were selected (Table 1)

Table 1

Process Parameters with their values at corresponding levels

\begin{tabular}{cccccc}
\hline S. No & Process Parameters & Range & Level & Level 2 & Level 3 \\
\hline 1 & Rotational Speed(RS) & $800-1600 \mathrm{rpm}$ & 800 & 1200 & 1600 \\
2 & Traverse Speed(TS) & $0.35-1.5 \mathrm{~mm} / \mathrm{s}$ & 0.35 & 0.7 & 1.2 \\
3 & Axial Force(AF) & $1000-7000 \mathrm{~N}$ & 3000 & 5000 & 7000 \\
\hline
\end{tabular}




\section{Materials and Methodology}

The base materials selected for this investigation were AA6351-T6 and AA2024-T6 aluminum alloys sheets of $5 \mathrm{~mm}$ thickness having chemical composition and mechanical properties shown in the Table 2 and 3. In the present study, sheets of size 200mm x 70mm of AA6351-T6 and AA2024-T6 were cut for welding by FSW (Fig.1). The AA6351-T6 alloy sheet was located on the retreating side and AA2024T6 was placed on the advancing side. The rotating tool used in this study was made of high-speed tool steel (Fig.2).

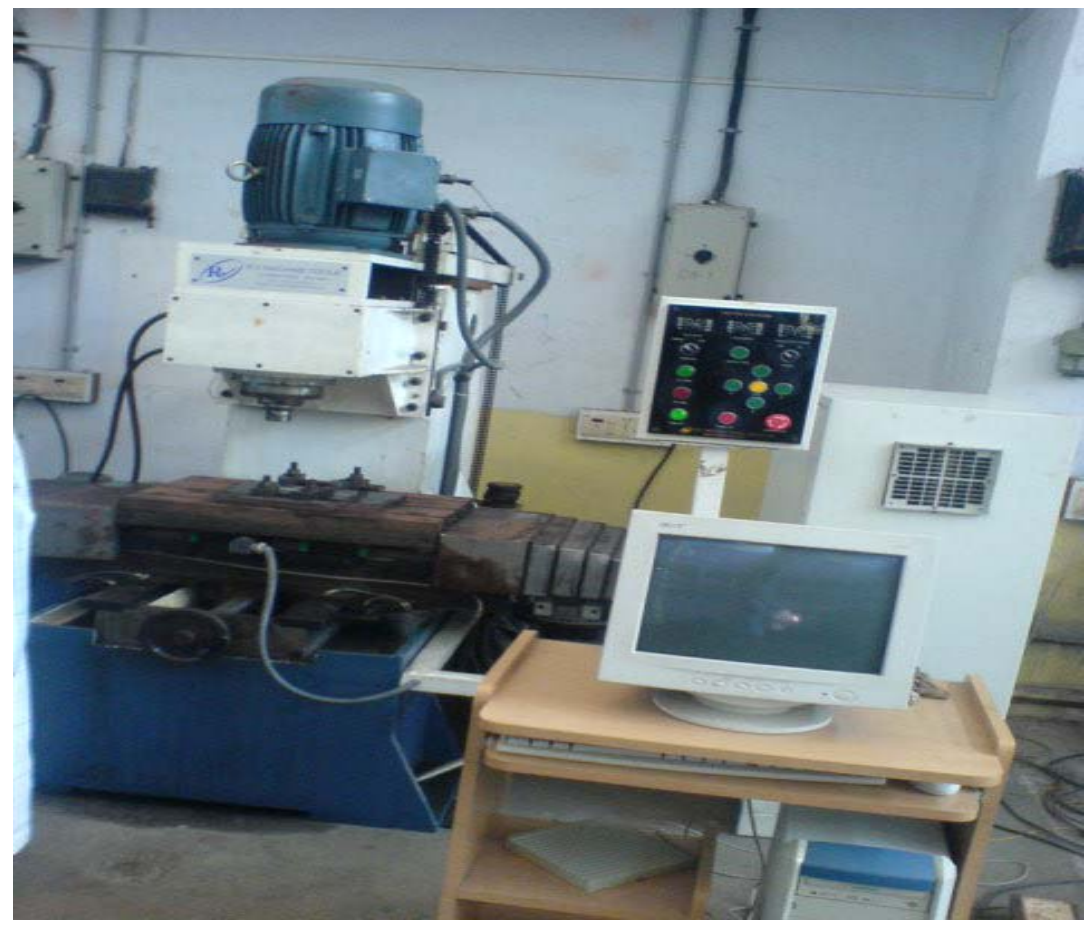

Fig.1. Experimental set up

Transverse tensile tests were performed in order to evaluate the tensile properties of the joints obtained by FSW process of the two dissimilar materials. To determine the tensile strength of the stir zone (SZ), tensile test specimens were sectioned as per ASTM-E8 (Fig.3) in the transverse direction perpendicular to the weld line with an electrical discharge machine (EDM). Tensile test specimen as shown in the Fig.4

Table 2

Chemical Composition of base materials AA2024-T6 and AA6351-T6

\begin{tabular}{ccccccc}
\hline Material & $\mathrm{Si}$ & $\mathrm{Fe}$ & $\mathrm{Cu}$ & $\mathrm{Mn}$ & $\mathrm{Mg}$ & $\mathrm{Al}$ \\
\hline $\mathrm{AA2024}$ & 0.118 & 0.209 & 3.99 & 0.53 & 1.28 & Bal. \\
$\mathrm{AA6351}$ & 1.040 & 0.372 & 1.20 & 0.65 & 1.14 & Bal. \\
\hline
\end{tabular}

Table 3

Mechanical properties of base materials AA2024-T6 and AA6351-T6

\begin{tabular}{cccc}
\hline Material & $\begin{array}{c}\text { UTS } \\
(\mathrm{Mpa})\end{array}$ & $\begin{array}{c}(\%) \\
\text { Elongation }\end{array}$ & $\begin{array}{c}\text { Micro Vickers } \\
\text { Hardness(VHN) (0.1kgf) }\end{array}$ \\
\hline AA2024 & 496 & 10.54 & 122.2 \\
AA6351 & 329 & 11.7 & 98.34 \\
\hline
\end{tabular}




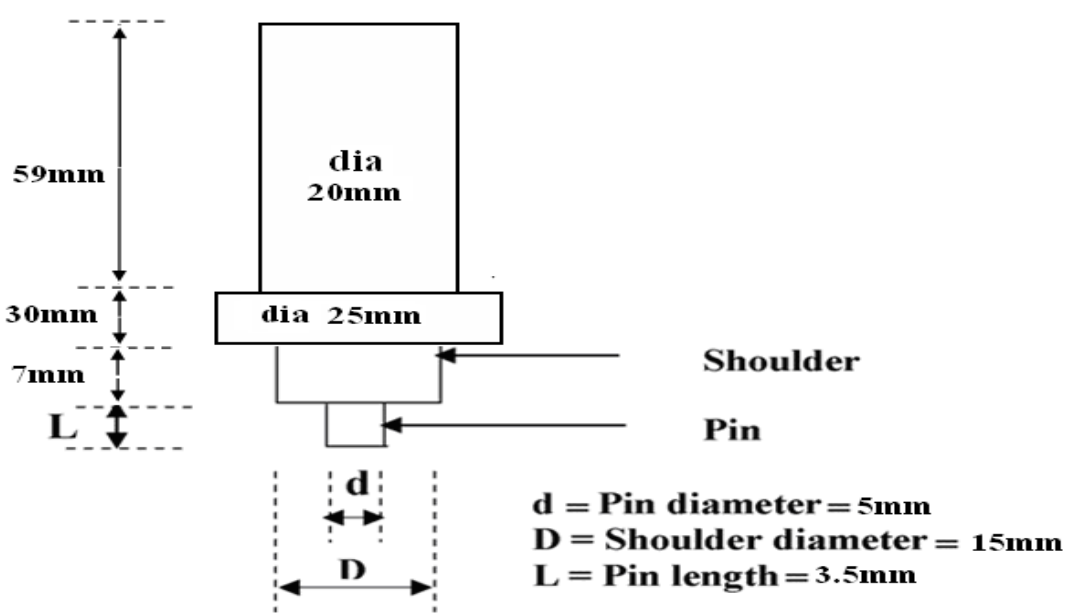

Fig. 2 Geometry of the rotating tool

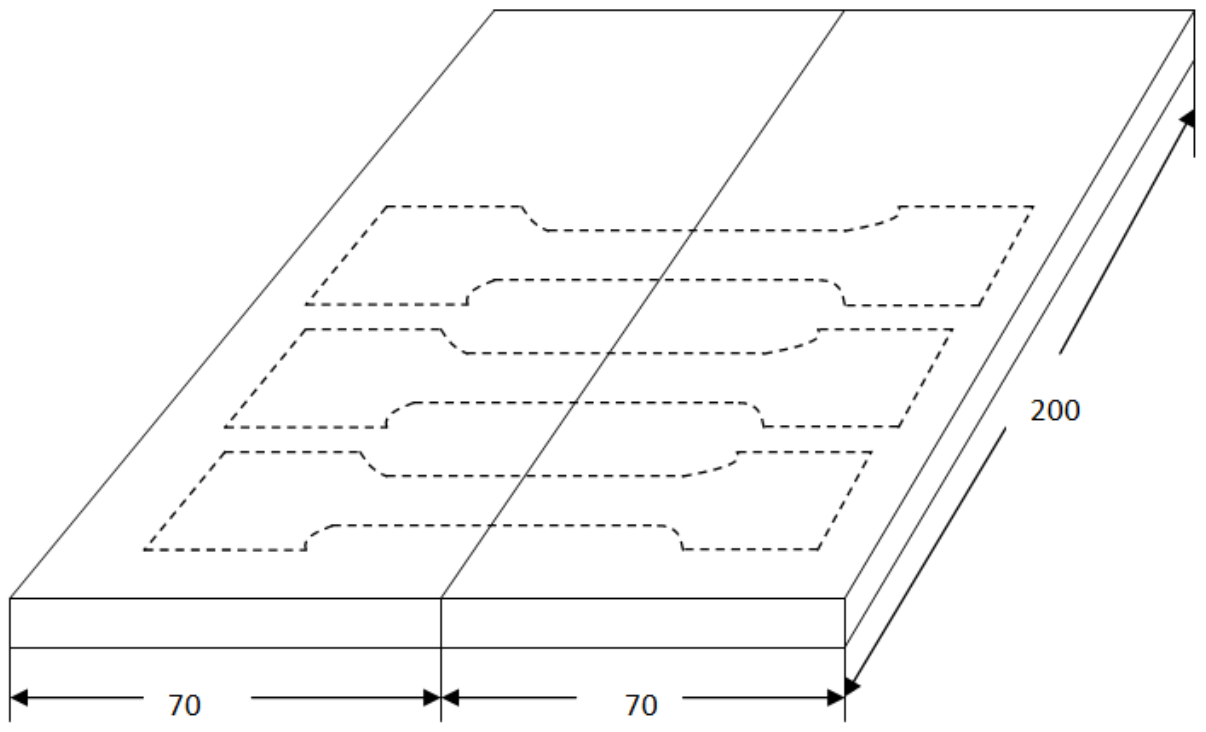

Fig. 3. Schematic view of the FS Welded Joint with the extraction of tensile specimens

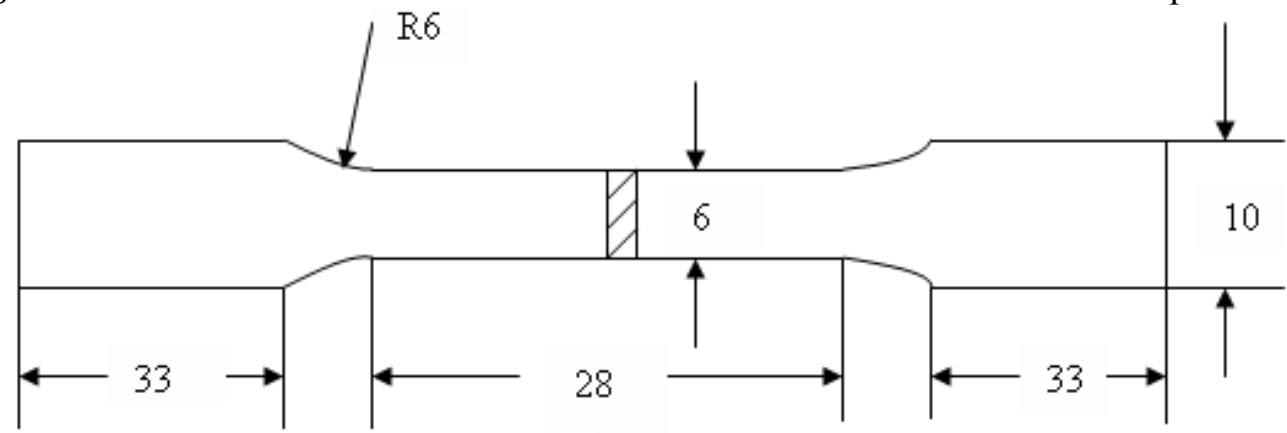

\section{Results and discussions}

Fig. 4. Tensile Test Specimen

\subsection{Signals to Noise Ratio}

Tensile strength is one of the main characteristics considered in this investigation describing the quality of FSW joints. Each control factor can be calculated in order to assess the influence of parameters on the response, the means and signal-to-noise $(\mathrm{S} / \mathrm{N})$ ratios. The signals are indicators of the effect on 
average responses and the noises are measures of the influence on the deviations from the sensitiveness of the experiment. The appropriate $\mathrm{S} / \mathrm{N}$ ratio must be chosen using previous knowledge, expertise, and understanding of the process. When the target is fixed and there is trivial or absent signal factor (static design), it is possible to choose the signal-to-noise $(\mathrm{S} / \mathrm{N})$ ratio depending on the goal of the design (Phadke, 1989). In this study, the $\mathrm{S} / \mathrm{N}$ ratio was chosen according to the criterion of the larger the better, in order to maximize the response. In Taguchi method, the signal to noise ratio is used to determine the deviation of the quality characteristics from the desired value. The $\mathrm{S} / \mathrm{N}$ ratio (larger-thebetter) can be expressed as

SN ratio $=-10 \log \left\{\frac{1}{n} \sum_{i=1}^{n}\left(\frac{1}{y_{i}{ }^{2}}\right)\right\}$,

where $n$ is the number of tests conducted, $y_{i}$ is the average observed data of each test. In the present study, the tensile strength data were analyzed to determine the effect of FSW process parameters. The experimental results were then transformed into means and signal-to-noise $(\mathrm{S} / \mathrm{N})$ ratio. In this work, 27 means and $27 \mathrm{~S} / \mathrm{N}$ ratios were calculated and the estimated tensile strength, means and signal-to-noise $(\mathrm{S} / \mathrm{N})$ ratio are given in Table 4.

\section{Table 4}

Mean and S/N ratio of tensile strength of FS Welds

\begin{tabular}{|c|c|c|c|c|c|}
\hline S.no & $\begin{array}{c}\text { Rotational } \\
\text { Speed(RS) } \\
(\mathrm{rpm})\end{array}$ & $\begin{array}{c}\text { Traverse } \\
\text { Speed(TS) } \\
(\mathrm{mm} / \mathrm{s})\end{array}$ & $\begin{array}{c}\text { Axial } \\
\text { Force(AF) } \\
(\mathrm{N})\end{array}$ & $\begin{array}{c}\text { Mean UTS } \\
(\mathrm{Mpa})\end{array}$ & S/N Ratio \\
\hline 1 & 800 & 0.35 & 3000 & 210 & 46.4444 \\
\hline 2 & 800 & 0.35 & 5000 & 215 & 46.6488 \\
\hline 3 & 800 & 0.35 & 7000 & 223 & 46.9661 \\
\hline 4 & 800 & 0.7 & 3000 & 212 & 46.5267 \\
\hline 5 & 800 & 0.7 & 5000 & 220.5 & 46.8682 \\
\hline 6 & 800 & 0.7 & 7000 & 226 & 47.0822 \\
\hline 7 & 800 & 1.2 & 3000 & 211 & 46.4856 \\
\hline 8 & 800 & 1.2 & 5000 & 213.4 & 46.5839 \\
\hline 9 & 800 & 1.2 & 7000 & 216 & 46.6891 \\
\hline 10 & 1200 & 0.35 & 3000 & 245 & 47.7833 \\
\hline 11 & 1200 & 0.35 & 5000 & 250 & 47.9588 \\
\hline 12 & 1200 & 0.35 & 7000 & 254 & 48.0967 \\
\hline 13 & 1200 & 0.7 & 3000 & 243 & 47.7121 \\
\hline 14 & 1200 & 0.7 & 5000 & 256 & 48.1648 \\
\hline 15 & 1200 & 0.7 & 7000 & 263 & 48.3991 \\
\hline 16 & 1200 & 1.2 & 3000 & 226 & 47.0822 \\
\hline 17 & 1200 & 1.2 & 5000 & 238 & 47.5315 \\
\hline 18 & 1200 & 1.2 & 7000 & 243 & 47.7121 \\
\hline 19 & 1600 & 0.35 & 3000 & 228 & 47.1587 \\
\hline 20 & 1600 & 0.35 & 5000 & 232.1 & 47.3135 \\
\hline 21 & 1600 & 0.35 & 7000 & 241 & 47.6403 \\
\hline 22 & 1600 & 0.7 & 3000 & 231 & 47.2722 \\
\hline 23 & 1600 & 0.7 & 5000 & 240 & 47.6042 \\
\hline 23 & 1600 & 0.7 & 7000 & 251 & 47.9935 \\
\hline 25 & 1600 & 1.2 & 3000 & 217 & 46.7292 \\
\hline 26 & 1600 & 1.2 & 5000 & 225 & 47.0437 \\
\hline 27 & 1600 & 1.2 & 7000 & 232 & 47.3098 \\
\hline
\end{tabular}

The analysis of mean for each of the experiments will give the better combination of parameters levels that ensures a high level of tensile strength according to the experimental set of data. The mean response refers to the average value of performance characteristics for each parameter at different levels. The mean for one level was calculated as the average of all responses that were obtained with 
that level. The mean response of raw data and $\mathrm{S} / \mathrm{N}$ ratio of tensile strength for each parameter at level 1 , 2 , and 3 were calculated and are given in Table 5 . The means and $\mathrm{S} / \mathrm{N}$ ratio of the various process parameters when they changed from the lower to higher levels are also given in Table: 5. It is clear that a larger $\mathrm{S} / \mathrm{N}$ ratio corresponds to better quality characteristics. Therefore, the optimal level of process parameter is the level of highest $\mathrm{S} / \mathrm{N}$ ratio (Sharma et al., 2005). The mean and $\mathrm{S} / \mathrm{N}$ ratio (Table 5.) for tensile strength were calculated by statistical software, indicating that the tensile strength was at maximum when rotational speed at $1200 \mathrm{rpm}$, traverse speed at $1.2 \mathrm{~mm} / \mathrm{s}$ and axial force at $7000 \mathrm{~N}$. The comparison of mean and $\mathrm{S} / \mathrm{N}$ ratio are presented in Fig: 4

Table 5

Main effects of tensile strength (Means and $\mathrm{S} / \mathrm{N}$ ratio)

\begin{tabular}{rccccccc}
\hline & Levels & \multicolumn{3}{c}{ Means } & \multicolumn{3}{c}{ S/N Ratio } \\
\cline { 3 - 8 } Process Parameter & & RS & TS & AF & RS & TS & AF \\
\hline & L1 & 216.3 & 233.1 & 224.8 & 46.70 & 47.33 & 47.02 \\
& L2 & 246.4 & 238.1 & 232.2 & 47.83 & 47.51 & 47.30 \\
& L3 & 233.0 & 224.6 & 238.8 & 47.34 & 47.02 & 47.54 \\
\hline Delta & & 30.1 & 13.5 & 14.0 & 1.13 & 0.50 & 0.52 \\
\hline
\end{tabular}

\subsection{Analysis of variance (ANOVA)}

Analysis of variance (ANOVA) test was performed to identify the process parameters that are statistically significant. The purpose of the ANOVA test is to investigate the significance of the process parameters which affect the tensile strength of FSW joints. The ANOVA results for tensile strength of means and $\mathrm{S} / \mathrm{N}$ ratio are given in Table 4 . In addition, the F-test named after Fisher can also be used to determine which process has a significant effect on tensile strength. Usually, the change of the process parameter has a significant effect on the quality characteristics, when $F$ is large (Table 6 and 7). The results of ANOVA indicate that the considered process parameters are highly significant factors affecting the tensile strength of FSW joints in the order of rotational speed, axial force and traverse speed. Effects of interaction between process parameters are not significant.

\section{Table 6}

ANOVA of tensile strength (Means)

\begin{tabular}{cccccccc}
\hline Source & DF & Seq SS & Adj SS & Adj MS & F & P & \% of contribution \\
\hline RS & 2 & 4098.97 & 4098.97 & 2049.48 & 149.67 & 0.000 & 67.31 \\
TS & 2 & 834.05 & 834.05 & 417.03 & 30.45 & 0.000 & 13.70 \\
AF & 2 & 883.19 & 883.19 & 441.59 & 32.25 & 0.000 & 14.50 \\
Error & 20 & 273.87 & 273.87 & 13.69 & & & 04.49 \\
\hline Total & 26 & 6090.07 & & & & 100 \\
\hline
\end{tabular}

DF-Degrees of freedom, Seq SS-Sequencial sum of squares, Adj SS-Adjusted sum of square, Adj MS-Adjusted mean square,F-Fisher ratio, $\mathrm{P}-$ probability that exceeds the $95 \%$ confidence level.

Table 7

ANOVA of tensile strength (S/N Ratio)

\begin{tabular}{|c|c|c|c|c|c|c|c|}
\hline \multicolumn{8}{|c|}{ S/N Ratio } \\
\hline Source & DF & Seq SS & Adj SS & Adj MS & $\mathrm{F}$ & $\mathrm{P}$ & $\%$ of contribution \\
\hline RS & 2 & 5.7547 & 5.7547 & 2.8773 & 172.36 & 0.000 & 68.13 \\
\hline TS & 2 & 1.1312 & 1.1312 & 0.5656 & 33.88 & 0.000 & 13.40 \\
\hline $\mathrm{AF}$ & 2 & 1.2265 & 1.2265 & 0.6133 & 36.74 & 0.000 & 14.52 \\
\hline Error & 20 & 0.3339 & 0.3339 & 0.0167 & & & 03.95 \\
\hline Total & 26 & 8.4463 & & & & & \\
\hline
\end{tabular}

DF-Degrees of freedom, Seq SS-Sequencial sum of squares, Adj SS-Adjusted sum of square, Adj MS-Adjusted mean square,F-Fisher ratio, $\mathrm{P}-$ probability that exceeds the $95 \%$ confidence level. 


\subsection{Optimizing the Tensile strength Properties}

Analyzing means and $\mathrm{S} / \mathrm{N}$ ratio of various process parameters (table 3 ), it is observed that a larger $\mathrm{S} / \mathrm{N}$ ratio corresponds to better quality characteristics. Therefore, optimal level of process parameter is the level of highest $\mathrm{S} / \mathrm{N}$ ratio (Sharma et al., 2005). Mean and $\mathrm{S} / \mathrm{N}$ ratio for ultimate TS was at maximum when

1. Rotational speed (level 2) of $1200 \mathrm{rpm}$,

2. Traverse speed (level 2) of $1.2 \mathrm{~mm} / \mathrm{s}$

3. Axial force (level 3) of $7000 \mathrm{~N}$
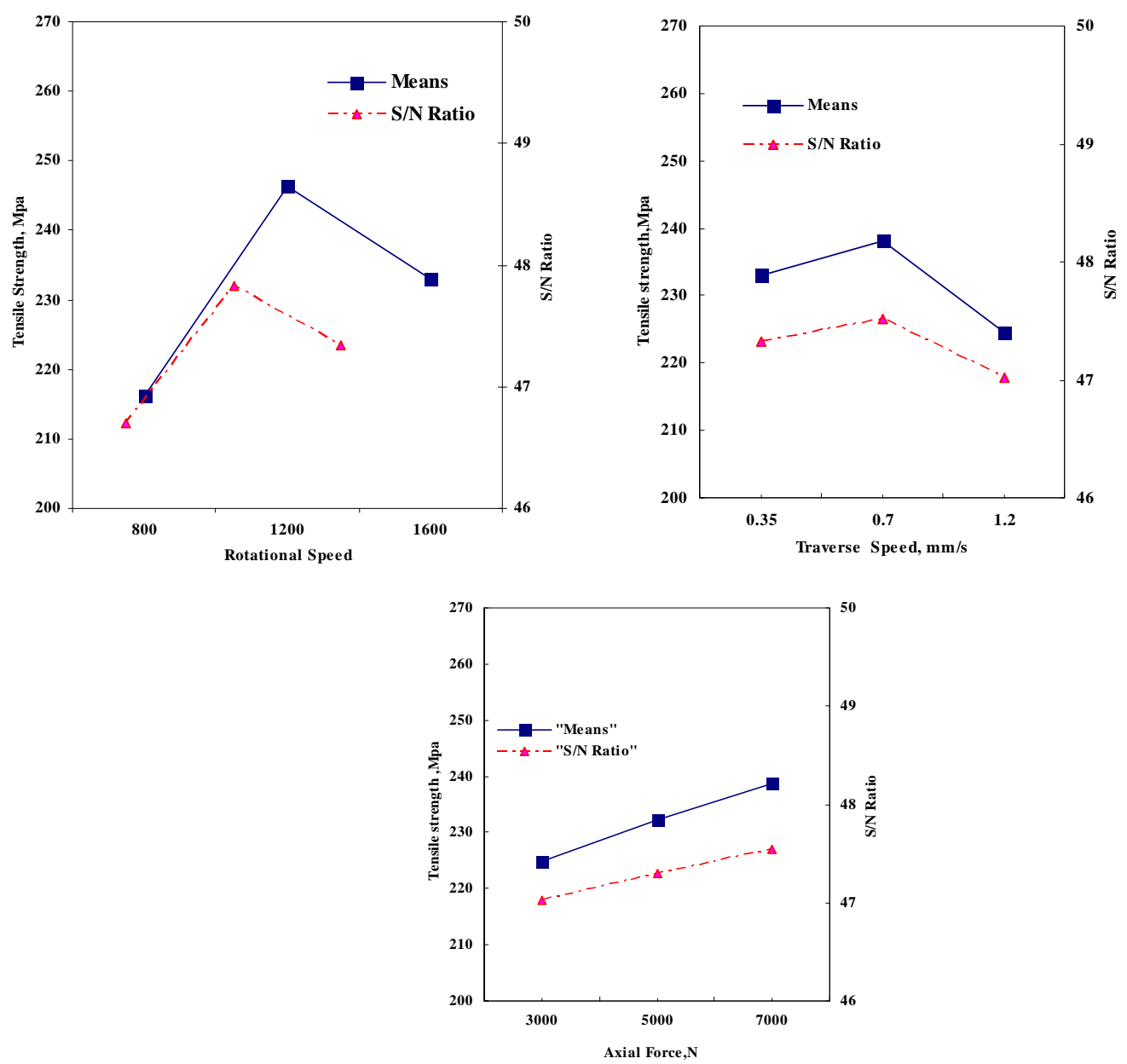

Fig.5. Response graphs of Means and $\mathrm{S} / \mathrm{N}$ ratio of tensile strength

\subsection{Estimation of optimum performance characteristics}

Optimum value of UTS was predicted at selected levels of significant parameters. Significant process parameters and their optimum levels have already been selected as rotational speed (level 2)of 1200 $\mathrm{rpm}$ and traverse speed(level 2) of $1.2 \mathrm{~mm} / \mathrm{s}$ and axial force( level 3) $7000 \mathrm{~N}$ (Table 4 ).Estimated mean of response characteristics (.UTS) can be calculated as

Ultimate tensile strength (UTS) $=$ Average UTS $($ AUTS $)+\left(R_{2}-\right.$ AUTS $)+\left(T_{2}-A U T S\right)+\left(\right.$ AF $\left._{3}-A U T S\right)$

$$
=231.9+(246.4-231.9)+238.1-231.9)+(238.8-231.9)=259.5 \mathrm{Mpa} \text {, }
$$


where UTS overall mean of ultimate tensile strength, $\mathrm{RS}_{2}$ average tensile strength of rotational speed at level 2, $\mathrm{TS}_{2}$ average tensile strength of traverse speed at level 2, $\mathrm{AF}_{3}$ average tensile strength of axial force at level 3.

\subsection{Conformation testing}

Conformation experiments were conducted at optimum setting of process parameters. rotational speed (level 2)of $1200 \mathrm{rpm}$ and traverse speed(level 2) of $1.2 \mathrm{~mm} / \mathrm{s}$ and axial force( level 3) $7000 \mathrm{~N}$ were set and average UTS was found to be $262 \mathrm{Mpa}$, which was within confidence intervals of predicted optimal UTS. The microstructure of traverse section of FS welded joint at optimum parameters reveals that there was no defect due to sufficient heat generation and also it was found that the fine grain structure caused for strength.

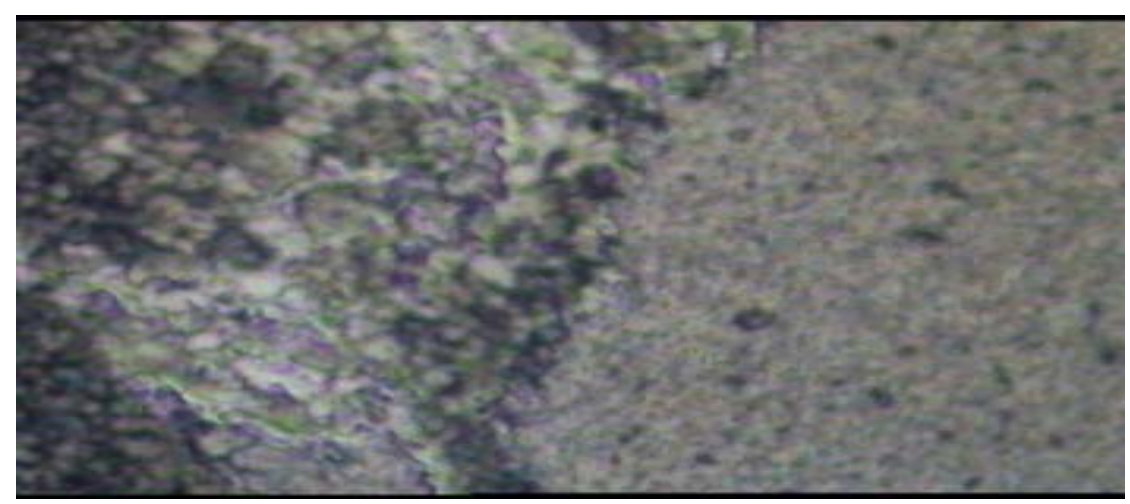

Fig. 6. Optical microstructure of SZ at optimized condition

\subsection{Development of the mathematical model ( Non-linear regression model )}

The ultimate Tensile strength is the function of Rotational speed, Traverse speed and axial force and it can be expressed as

$Y=f(R S, T S, A F)$,

where $\mathrm{Y}$ is the response known as UTS.

For the three factors, the selected regression polynomial could be as

$Y=b_{0}+b_{1} R S+b_{2} T S+b_{3} A F+b_{12} R S^{*} T S+b_{23} T S * A F+b_{31} A F^{*} R S+b_{11} R S^{2}+b_{22} T S^{2}+b_{33} A F^{2}$,

where $b_{0}$ is a constant, $b 1, b_{2}, b_{3}$ are linear terms, $b_{11}, b_{22}, b_{33}$ quadratic terms and $b_{12}, b_{23}, b_{31}$ are interaction terms. To correlate the process parameters UTS values, a non-linear regression model was developed to predict the UTS of FS Welds of AA 2024-T6 and AA 6351-T6 aluminum alloys. Regression coefficients were calculated by using statistical software MINI TAB 15.0. After determining the coefficients, final model was developed with these coefficients to determine UTS,

$$
\begin{aligned}
U T S= & -9.1+0.347 * R S+77 * T S+0.00251 * A F-0.0111 * R S * T S+0.0001 * T S * A F+0.000001 * R A * A F \\
& -0.000135 * R S^{2}-47.7 * T S^{2}-0.0 * A F^{2}
\end{aligned}
$$

The model was tested by using ANOVA .All terms including RS, TS, AF, $\mathrm{RS}^{2}, \mathrm{TS}^{2}$, were found to be significant at $95 \%$ confidence interval. The goodness of the fit of the model was verified by knowing the $R^{2}$ (96.5) values. The value of adjusted $R^{2}(94.6)$ is also high, which indicates a high significant of the model. Besides, the diagnostic checking has been performed through residual analysis. The 
residual plots for tensile strength are shown in Fig. 7 and 8. These were fall on the straight line implying that errors were distributed normally. Almost, the values are within the confidence level 95\%. Hence, these values yielded better results in future prediction.

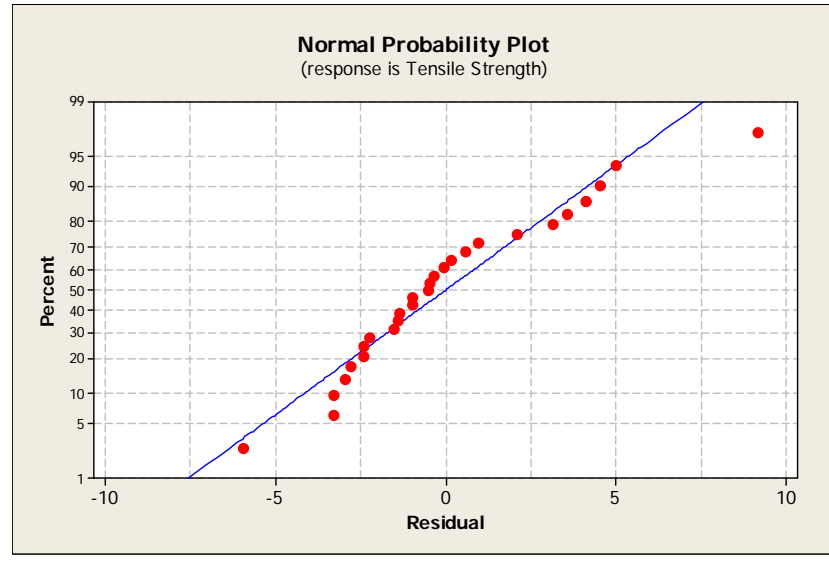

Fig. 7. Normal probability of the residuals for Tensile strength

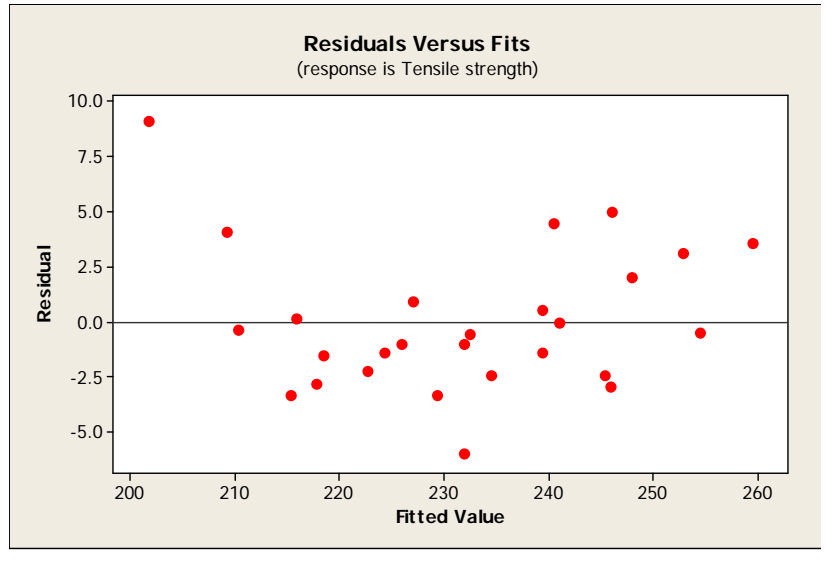

Fig. 8. Residuals versus fitted values for Tensile strength

\section{Conclusions}

The following conclusions have been derived by applying ANOVA on the experimental investigations of AA 6351-T6 and AA 2024-T6 alloys by FSW.

- The optimum value of process parameters such as rotational speed, traverse speed and axial force are found to be $1200 \mathrm{rpm}$ ( level 2), $1.2 \mathrm{~mm} / \mathrm{s}($ level 2) and $7000 \mathrm{~N}$ ( level 3) respectively

- The optimum parameters were evaluated and the percentage of contribution of FSW process parameters was evaluated. It was found that the tool rotational speed had $67.31 \%$ contribution, traverse speed had $13.7 \%$ contribution and axial force had $14.5 \%$ contribution in yield of welded joints.

- The predicted tensile strength by the model is fairly accurate and it was also concluded with the analysis of residual plots which did not indicate any model inadequacy.

\section{Acknowledgements}

The authors are grateful to the Department of Metallurgical and Materials Engineering, IITM, Chennai, Tamil Nadu, India for extending the facilities of Metal Joining Laboratory to carry out the experiments. The authors also wish to express their sincere thanks to Mechanical Engineering Department, Osmania University to carry out the investigations

\section{References}

Thomas, W. M., Nicholas, E. D., Needam, J. C., Murch, M. G., Templesmith, P. \& Dawes, C. J (1991). GB Patent Application No. 9125978.8, December 1991 and US Patent No. 5460317, October 1995.

Lee, W.-B., Yeon, Y.-M., \& Jung, S.-B. (2003). The Joint Properties of Dissimilar Formed Al Alloys by Friction Stir Welding According to the Fixed Location of Materials. Scripta Materialia, 49, 423428.

Bussu, G., \& Irving, P. E. (2003). The Role of Residual Stress and Heat Affected Zone Properties on Fatigue Crack Propagation in Friction Stir Welded 2024-T351 Aluminium Joints. International Journal of Fatigue, 25, 77-88. 
John, R., Jata, K.V., \& Sadananda, K. (2003). Residual Stress Effects on near Threshold Fatigue Crack Growth in Friction Stir Welded Aerospace Alloys. International Journal of Fatigue, 25, 939-948.

Jata, K. V., Sankaran, K. K., \& Ruschau, J. (2000). Friction-Stir Welding Effects on Microstructure and Fatigue of Aluminum Alloy 7050-T7451. Metallurgical and Materials Transactions, 31A, 21812192.

Montgomery, D. C. (2006). Design and analysis of experiments, IV Edition. NY: John-Wiley \& Sons, Inc.,

Ross, P. J. (1988). Taguchi techniques for quality engineering. NY: Tata McGraw Hill,

Phadke, M. S. (1989). Quality engineering using robust design. NJ, USA: PTR, Prentice Hall, Englewood Cliffs,

Sharma, P., Verma, A., Sidhu, R.K., \& Pandey, O.P. (2005). Process parameter selection for strontium ferrite sintered magnets using Taguchi L9 orthogonal design. Journal Material Processing Technology, 168, 147-151.

MINITAB Statistical software Release 15.0. 